\title{
Evaluation of the Use of Acacia nilotica Leaf as an Ecofriendly Adsorbent for Cr (VI) and Its Suitability in Real Waste Water: Study of Residual Errors
}

\author{
Ashly Leena Prasad and Santhi Thirumalisamy \\ Department of Chemistry, Karpagam University, Coimbatore 641021, India \\ Correspondence should be addressed to Santhi Thirumalisamy; ssnilasri@yahoo.co.in
}

Received 28 November 2011; Revised 27 May 2012; Accepted 28 May 2012

Academic Editor: José Morillo Aguado

Copyright (C) 2013 A. L. Prasad and S. Thirumalisamy. This is an open access article distributed under the Creative Commons Attribution License, which permits unrestricted use, distribution, and reproduction in any medium, provided the original work is properly cited.

\begin{abstract}
The present paper aims to investigate the physical characteristics of Acacia nilotica leaves (MVM) relative to their use as an adsorbent for removal of hazardous $\mathrm{Cr}$ (VI) from waste water. The adsorbent was characterized by FTIR and SEM studies. The applicability of the Langmuir model to MVM was proved by the high coefficient of determination. Eight error analysis methods, namely, residual root mean square error (RMSE), chi-square $\left(\chi^{2}\right)$, sum of the square of the errors (ERRSQ), composite functional error (HYBRD), derivative of Marquardt's percent standard deviation (MPSD), average relative error (ARE), sum of absolute error (EABS), and average percentage error (APE) were used to evaluate the suitability of the adsorption isotherm. Desorption reveals that recovery of the metal from adsorbent was possible. The ecofriendly adsorbent MVM is expected to be an environmentally and economically feasible adsorbent for the removal of $\mathrm{Cr}$ (VI) from aqueous solution and real waste water.
\end{abstract}

\section{Introduction}

Mobilization of heavy metals in the environment due to industrial activities is of serious concern as these metals are toxic to all forms of life including humans [1]. Chromium compounds are widely used in various industries, such as, electroplating, metal finishing, leather tanning, and chromate preparation, and as a result they are often found in industrial waste waters [2]. Chromium occurs in natural water is in two main oxidation states, $\mathrm{Cr}$ (III) and $\mathrm{Cr}$ (VI). Although $\mathrm{Cr}$ (III) is an essential nutrient in mammalian metabolism, $\mathrm{Cr}$ (VI) is highly toxic and mutagenic. The recommended limit for $\mathrm{Cr}(\mathrm{VI})$ in potable water is $0.05 \mathrm{mg} \mathrm{dm}^{-3}$. Acacia nilotica is a species of Acacia, native to Africa and the Indian subcontinent. In Haryana, Acacia-nilotica-based agro forestry systems reduced the yield of wheat [3]. In this paper the preparation, characterization, and the adsorption properties of microwave activated carbon from Acacia nilotica leaves are discussed. The microwave activation method was used because of its one-step simple process.

\section{Experimental}

2.1. Preparation and Characterization of Sorbent. The leaves of Acacia nilotica were obtained from Coimbatore district (Tamilnadu), were washed with distilled water, air-dried, and heated in a microwave oven (Samsung; Triple Distribution System) at $800 \mathrm{~W}$ for 5 minutes. The carbonized sample (MVM) was crushed into granules, sieved to different particle sizes $(125$ to $250 \mu \mathrm{m})$, and then preserved in an air-tight container for further studies. The surface morphology and fundamental physical properties of the sorbent were obtained by the scanning electron microscope (LEO 435 VP model) and Fourier Transform Infrared (FTIR) analysis (Shimadzu spec).

Determination of zero point charge $\left(\mathrm{pH}_{\mathrm{zpc}}\right)$ was done to investigate the surface charge of the adsorbent. For the determination of $\mathrm{pH}_{\mathrm{zpc}}, 1 \mathrm{~g}$ of the sample suspension (particle size: 125 to $250 \mu \mathrm{m}$ ) was prepared in $50 \mathrm{~mL}$ solution of sodium nitrate electrolyte of concentration $10^{-2} \mathrm{M}$. The aliquots of suspension were adjusted to various $\mathrm{pH}$ values 
with dilute $\mathrm{NaOH}$ and $\mathrm{HNO}_{3}$ solution. After 60 minutes for equilibrium, the initial $\mathrm{pH}$ value is measured.Then $1 \mathrm{~g}$ of $\mathrm{NaNO}_{3}$ was added to each aliquot to bring final electrolyte concentration to about $0.45 \mathrm{M}$.After an additional 60 minutes agitation, final $\mathrm{pH}$ was measured. The results were plotted with $\Delta \mathrm{pH}$ (final $\mathrm{pH}-$ initial $\mathrm{pH}$ ) against final $\mathrm{pH}$. The point of intersection of the resulting curve with abscissa, at which $\mathrm{pH}=0$, gave the $\mathrm{pH}_{\mathrm{zpc}}[4]$.

\subsection{Metal Uptake Experiments and Determining Isotherm} Parameters by Nonlinear Regression. The stock solution $(3.39 \mathrm{mmol} / \mathrm{L})$ was prepared by dissolving $2.827 \mathrm{~g}$ of potassium dichromate $\left(\mathrm{K}_{2} \mathrm{Cr}_{2} \mathrm{O}_{7}\right)$ in double-distilled water. For each isotherm, a series of flasks were prepared with known volumes of serial dilutions of standardized metal salt solutions $(2.03,2.37,2.71,3.05$, and $3.39 \mathrm{mmol} / \mathrm{L}$, resp.). The $\mathrm{pH}$ was adjusted with $0.1 \mathrm{M} \mathrm{HCl}$ or $0.1 \mathrm{M} \mathrm{NaOH}$ (pH from 2 to 8) by 1,5-diphenylcarbazide method was measured using a $\mathrm{pH}$ meter (Deluxe $\mathrm{pH}$ meter, model-101 E, Innolab India) with a combined glass electrode calibrated with buffer. About $0.4 \mathrm{~g}$ of the sorbent was added, and the flasks were agitated at $160 \mathrm{rpm}$ for 90 minutes. The sorbent was removed by centrifugation, and the supernatant was analyzed. The concentration was measured by using direct UV-vis spectrophotometric method using a Systronic Spectrophotometer-104 at wavelength of $430 \mathrm{~nm}$. Desorption studies were carried out by filtering the metal loaded adsorbent with distilled water and adjusting the initial $\mathrm{pH}$ values from 2 to 7 . The desorbed $\mathrm{Cr}$ (VI) in the solution was separated by centrifugation and analyzed and the $\%$ of desorption was calculated.

The amount of metal adsorbed at equilibrium $\left[q_{e}\right.$ $\left.\left(\mathrm{mmolg}^{-1}\right)\right]$ onto carbon was calculated by the following mass balance relationship:

$$
q_{e}=\left(C_{0}-C_{e}\right) V / W,
$$

where, $C_{0}$ and $C_{e}$ are the concentrations $\left(\mathrm{mmolL}^{-1}\right)$ of $\mathrm{Cr}$ (VI) at initial and at equilibrium, respectively. $V$ is the volume (L) of the solution and $W$ is the weight (g) of the adsorbent used.

Nonlinear analysis of isotherm data is an interesting mathematical approach for describing adsorption isotherms at constant temperature for water and waste water treatment and to predict the overall sorption behavior under different operating conditions [5]. The error functions employed were as follows.

(i) Residual root mean square error (RMSE) is

$$
\sqrt{\frac{1}{n-2} \sum_{i=1}^{N}\left(q_{e} \exp -q_{e} \mathrm{cal}\right)^{2}} .
$$

(ii) The $X$-square test is

$$
x^{2}=\sum_{i=1}^{N} \frac{\left(q_{e} \exp -q_{e} \mathrm{cal}\right)^{2}}{q_{e} \mathrm{cal}} .
$$

If data from the model are similar to the experimental data, then $\chi^{2}$ will be a smaller number; if they are different, then $\chi^{2}$ will be a large number. The subscript "exp" and "cal" shows the experimental and calculated values, and $N$ is the number of observations in the experimental data. The smaller the RMSE value, the better the curve fitting [6].

(iii) The sum of the square of the errors (ERRSQ) is

$$
\sum_{i=1}^{N}\left(q_{e} \exp -q_{e} \mathrm{cal}\right)_{i}^{2} .
$$

(iv) A composite fractional error function (HYBRD) is

$$
\sum_{i=1}^{N}\left[\frac{\left(q_{e} \exp -q_{e} \mathrm{cal}\right)^{2}}{q_{e} \exp }\right]_{i}
$$

(v) A derivative of Marquardt's percent standard deviation (MPSD) is

$$
\sum_{i=1}^{N}\left[\frac{\left(q_{e} \exp -q_{e} \mathrm{cal}\right)}{q_{e} \exp }\right]_{i}^{2} .
$$

(vi) The average relative error (ARE) is

$$
\sum_{i=1}^{N}\left[\frac{\left(q_{e} \exp -q_{e} \mathrm{cal}\right)}{q_{e} \exp }\right]_{i}
$$

(vii) The sum of absolute error (EABS) is

$$
\sum_{i=1}^{N}\left[q_{e} \exp -q_{e} \mathrm{cal}\right]_{i}
$$

(viii) The average percentage error (APE) is

$$
\sum_{i=1}^{N} \frac{\left[\left(q_{e} \exp -q_{e} \mathrm{cal}\right) / q_{e} \exp \right]_{i}}{N} \times 100
$$

The calculation method for the "sum of the normalized errors" was as follows.

(a) Select one isotherm and one error function and determine the isotherm parameters that minimize the error function for that isotherm to produce the isotherm parameter set for that error function.

(b) Determine the values for all the other error functions for that isotherm parameter set,calculate all other parameter sets and all their associated error function values for that isotherm.

(c) Select each error measure in turn and the ratio of the value of that error measure for a given parameter set to the largest value of that error from all the parameter sets for that isotherm.

(d) Get sum all these normalized errors for each parameter set.

The parameter set thus providing the smallest normalized error sum can be considered to be optimal for that isotherm provided. 


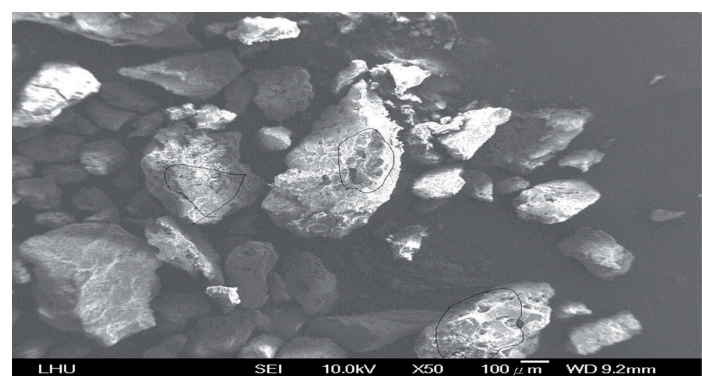

FIGURE 1: SEM image of MVM.

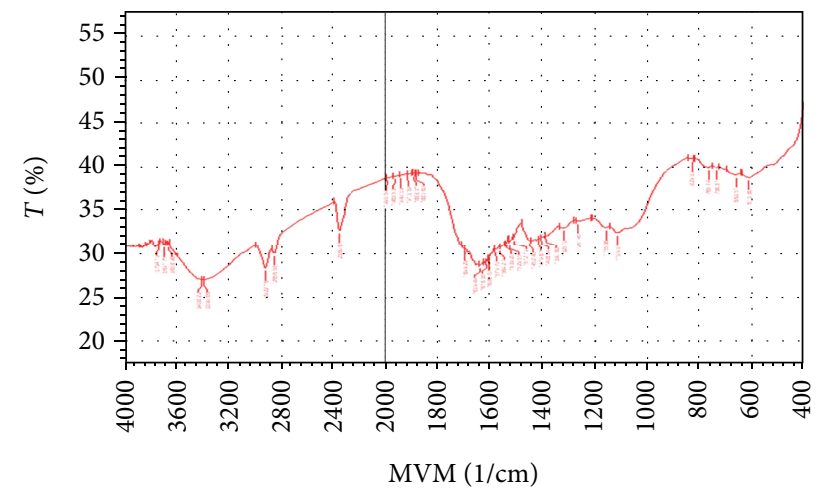

Figure 2: FTIR spectra of MVM.

\section{Results and Discussion}

SEM studies (Figure 1) show that MVM have considerable number of heterogeneous pores, where there is a good possibility for adsorbate to be trapped and adsorbed [7]. The FTIR spectrum of MVM (Figure 2) shows that the band at $3412 \mathrm{~cm}^{-1}$ represents the presence of $-\mathrm{OH}$ and $-\mathrm{NH}$ groups. The band observed at $2926 \mathrm{~cm}^{-1}$ and at $2856 \mathrm{~cm}^{-1}$ represents the presence of asymmetric and symmetric stretching vibrations of $-\mathrm{CH}$ group [8]. The bands at 1637 and $1452 \mathrm{~cm}^{-1}$ indicate the presence of $-\mathrm{COO},-\mathrm{C}=\mathrm{O}$, and $-\mathrm{NH}$ groups. The peak at $1564 \mathrm{~cm}^{-1}$ is attributed to the formation of oxygen functional groups, such as, a highly conjugated $\mathrm{C}-\mathrm{O}$ stretching in carboxylic groups and due to the presence of quinone structure. The bands at 1390 to $1408 \mathrm{~cm}^{-1}$ assigned to $\mathrm{C}-\mathrm{H}$ bending in alkanes or alkyl groups were observed. The broad band between 1325 and $1109 \mathrm{~cm}^{-1}$ has been assigned to $\mathrm{C}-\mathrm{O}$ stretching in alcohols and phenols [9]. The band at $1261 \mathrm{~cm}^{-1}$ implied the $\mathrm{C}-\mathrm{N}$ stretching of Amide ||| is present in MVM. The characteristics of MVM are presented in (Table 1).

The maximum adsorption capacity for $\mathrm{Cr}$ (VI) was observed at $\mathrm{pH} 6$, as depicted in Figure 3. The effect of solution $\mathrm{pH}$ is very important when the adsorbing molecules are capable of ionizing in response to the current $\mathrm{pH}$. Activated carbons are material that has amphoteric characteristics, so the $\mathrm{pH}$ on its surface always changes depending on initial $\mathrm{pH}$ of the solution. Generally, the adsorption capacity and the rate constant have the tendency to increase as initial $\mathrm{pH}$

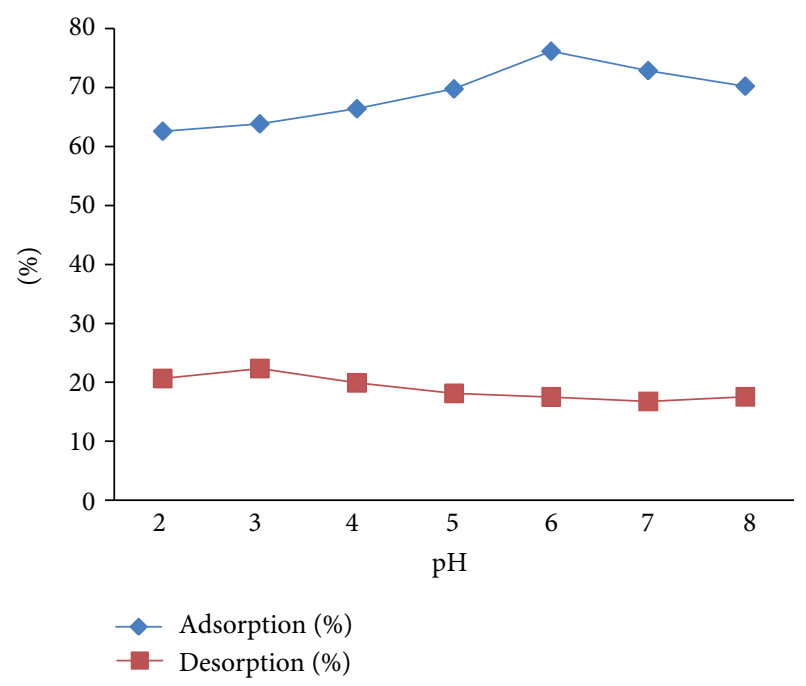

Figure 3: Percentage of adsorption and desorption of Cr (VI) onto MVM.

of the solution increases. When solution $\mathrm{pH}$ increases, high $\mathrm{OH}^{-}$ions accumulate on the adsorbent surface [8]. Therefore, electrostatic interaction between negatively charged adsorbent surface and cationic metal molecule caused the increase in adsorption. The optimum $\mathrm{pH}$ value of $\mathrm{Cr}$ (VI) onto MVM was $6 \mathrm{pH}$, and it was used for the subsequent experiments.

The equilibrium isotherms are used to describe experimental data. The adsorption isotherm is important from both a theoretical and a practical point of view. To optimize the design of an adsorption system it is important to establish the most appropriate correlation for the equilibrium curves [10]. The equation parameters of these equilibrium models often provide some insight into the sorption mechanism, the surface properties, and affinity of the adsorbent [11]. The adsorption isotherm equations like Langmuir, Freundlich, Dubinin-Radushkevich (D-R), and Temkin were used to describe the equilibrium characteristics of the adsorption.

The Langmuir isotherm theory assumes monolayer coverage of adsorbate over a homogeneous adsorbent surface [12]. Once a metal molecule occupies a site, no further adsorption can take place at that site. It is commonly expressed as follows:

$$
q_{e}=\frac{\left(Q_{m} K_{a} C_{e}\right)}{\left(1+K_{a} C_{e}\right)} .
$$

The Langmuir isotherm equation (10) can be linearized into the following form [13]:

$$
\frac{C_{e}}{q_{e}}=\frac{1}{K_{a} Q_{m}}+\left(\frac{1}{Q_{m}} \times C_{e}\right),
$$

where $q_{e}$ and $C_{e}$ are defined before in (1), $Q_{m}$ is a constant, reflecting a complete monolayer $\left(\mathrm{mgg}^{-1}\right) ; K_{a}$ is adsorption equilibrium constant $\left(\mathrm{Lmg}^{-1}\right)$ that is related to the apparent energy of sorption. A plot of $C_{e} / q_{e}$ versus $C_{e}$ should indicate a straight line of slope $1 / Q_{m}$ and an intercept of $1 /\left(K_{a} Q_{m}\right)$. 
TABLE 1: Physicochemical characteristics of MVM.

\begin{tabular}{lc}
\hline Parameters & Values \\
\hline Moisture content $(\%)$ & 8.713 \\
Ash content $(\%)$ & 9.950 \\
$\mathrm{pH}$ & 7.020 \\
Decolorizing power $\left(\mathrm{mgg}^{-1}\right)$ & 1.200 \\
Specific gravity & 1.220 \\
Matter soluble water $(\%)$ & 12.44 \\
Conductivity $\left(\mu \mathrm{scm}^{-1}\right)$ & 0.260 \\
Zero-point charge $\left(\mathrm{pH}_{\mathrm{zpc}}\right)$ & 4.400 \\
Apparent density $\left(\mathrm{gmL}^{-1}\right)$ & 0.272 \\
\hline
\end{tabular}

TABLE 2: Isotherm constants for $\mathrm{Cr}$ (VI) adsorption onto $0.4 \mathrm{~g}$ of MVM.

\begin{tabular}{lc}
\hline Isotherm model & Values \\
\hline Langmuir & \\
$Q_{m}\left(\mathrm{mgg}^{-1}\right)$ & 69.4440 \\
$b\left(\mathrm{Lmg}^{-1}\right)$ & 0.0296 \\
$R^{2}$ & 0.9984 \\
Freundlich & \\
$\quad 1 / n$ & 0.1079 \\
$K_{f}\left(\mathrm{mgg}^{-1}\right)$ & 33.3960 \\
$R^{2}$ & 0.9501 \\
Dubinin-Radushkevich & \\
$Q_{m}\left(\mathrm{mgg}^{-1}\right)$ & 64.3894 \\
$K\left(\mathrm{~mol}^{2} \mathrm{~kJ} J^{-2}\right)$ & 0.0004 \\
$E\left(\mathrm{kJmol}^{-1}\right)$ & 0.0353 \\
$R^{2}$ & 0.8395 \\
Temkin & \\
$\alpha\left(\mathrm{Lg}^{-1}\right)$ & 40.3360 \\
$\beta\left(\mathrm{mgL}^{-1}\right)$ & 6.5784 \\
$b$ & 379.1499 \\
$R^{2}$ & 0.9460 \\
\hline
\end{tabular}

The result obtained from the Langmuir model for the removal of $\mathrm{Cr}$ (VI) onto MVM is shown in Table 2. The related error function values are shown in Table 3 . These values are near the experimental adsorbed amounts and correspond closely to the adsorption isotherm plateau, which is acceptable. The correlation coefficient $\left(R^{2}=0.9984\right)$ showed strong positive evidence on the adsorption follows the Langmuir isotherm.

The Freundlich isotherm [9] can be applied to nonideal adsorption on heterogeneous surfaces as well as multilayer sorption. The Freundlich isotherm can be derived assuming a logarithmic decrease in enthalpy of adsorption with the increase in the fraction of occupied sites and is commonly given by the following nonlinear equation:

$$
q_{e}=K_{F} C_{e}^{1 / n}
$$

Equation (12) can be linearized in the logarithmic form (13), and the Freundlich constants can be determined:

$$
\log q_{e}=\log K_{F}+\frac{1}{n} \log C_{e} .
$$

A plot of $\log q_{e}$ versus $\log C_{e}$ enables us to determine the constant $K_{f}$ and $1 / n . K_{f}$ is roughly an indicator of the adsorption capacity, related to the bond energy, and $1 / n$ is the adsorption intensity of $\mathrm{Cr}$ (VI) onto the adsorbent of surface heterogeneity. The magnitude of the exponent, $1 / n$, gives an indication of the favorability of adsorption. A value for $1 / n$ below one indicates a normal Langmuir isotherm, while $1 / n$ above one is indicative of cooperative adsorption [14] and is equal to 0.1079 . It is lower than the experimental amounts corresponding to the adsorption isotherm plateau, which is unacceptable.

The D-R isotherm was also applied to estimate the porosity apparent free energy and the characteristics of adsorption $[15,16]$. It can be used to describe adsorption on both homogenous and heterogeneous surfaces [17]. The D-R equation can be defined by the following equation:

$$
\ln q_{e}=\ln Q_{m}-K \varepsilon^{2},
$$

where $K$ is a constant related to the adsorption energy, $Q_{m}$ the theoretical saturation capacity, and $\varepsilon$ is the Polanyi potential, calculated from (15),

$$
\varepsilon=R T \ln \left(1+\frac{1}{C_{e}}\right)
$$

where $C_{e}$ is the equilibrium concentration of $\mathrm{Cr}$ (VI) (molL $\left.{ }^{-1}\right), R$ is the gas constant $\left(8.314 \mathrm{~J} \mathrm{~mol}^{-1} \mathrm{~K}^{-1}\right)$, and $T$ is the temperature $(K)$. By plotting $\ln q_{e}$ versus $\varepsilon^{2}$, it is possible to determine the value of $K$ from the slope and the value of $Q_{m}\left(\mathrm{mgg}^{-1}\right)$ from the intercept. The mean free energy $E$ $\left(\mathrm{kJmol}^{-1}\right)$ of sorption can be estimated by using $K$ values as expressed in the following equation [18]:

$$
E=\frac{1}{\sqrt{2 K}}
$$

The parameters obtained using the above equations are summarized in Table 2. The saturation adsorption capacity $Q_{m}$ obtained using the D-R isotherm model is $64.3894 \mathrm{mgg}^{-1}$. The $E$ value calculated using (16) is $0.0353 \mathrm{kJmol}^{-1}$ for $\mathrm{Cr}$ (VI) adsorption onto MVM. This indicated that the physical adsorption plays the significant role in the uptake of $\mathrm{Cr}$ (VI) onto MVM [18]. The error functions indicate that the D-R isotherm is not fit in this adsorption.

Temkin and Pyzhey [19] considered the effects of some indirect adsorbate or adsorbate interactions on adsorption isotherms and suggested that because of these interactions the heat of adsorption of all the molecules in the layer would decrease linearly with coverage. The Temkin isotherm has commonly been applied in the following form:

$$
q_{e}=\frac{R T}{b} \ln \left(A C_{e}\right) .
$$


TABLE 3: Values of error function of the isotherm models of Cr (VI) onto MVM.

\begin{tabular}{lcccc}
\hline & Error function model & \multicolumn{2}{c}{ Isotherm model } \\
& Langmuir & Freundlich & D-R & Temkin \\
\hline RMSE & 13.918 & 14.3534 & 14.012 & 14.3268 \\
$\chi^{2}$ & $3.2 \times 10^{-7}$ & $4.2 \times 10^{-3}$ & $9.2 \times 10^{-4}$ & $3.9 \times 10^{-3}$ \\
ERRSQ & $2.0 \times 10^{-5}$ & 0.2615 & 0.0570 & 0.2455 \\
HYBRD & $3.2 \times 10^{-7}$ & $4.2 \times 10^{-3}$ & $9.2 \times 10^{-4}$ & $3.9 \times 10^{-3}$ \\
MPSD & $5.3 \times 10^{-9}$ & $6.9 \times 10^{-5}$ & $1.5 \times 10^{-5}$ & $6.4 \times 10^{-5}$ \\
ARE & $7.3 \times 10^{-5}$ & $8.3 \times 10^{-3}$ & $3.8 \times 10^{-3}$ & $8.0 \times 10^{-3}$ \\
EABS & 0.0045 & 0.5114 & 0.2388 & 0.4955 \\
APE & $1.4 \times 10^{-3}$ & 0.1663 & 0.0776 & 0.1612 \\
\hline
\end{tabular}

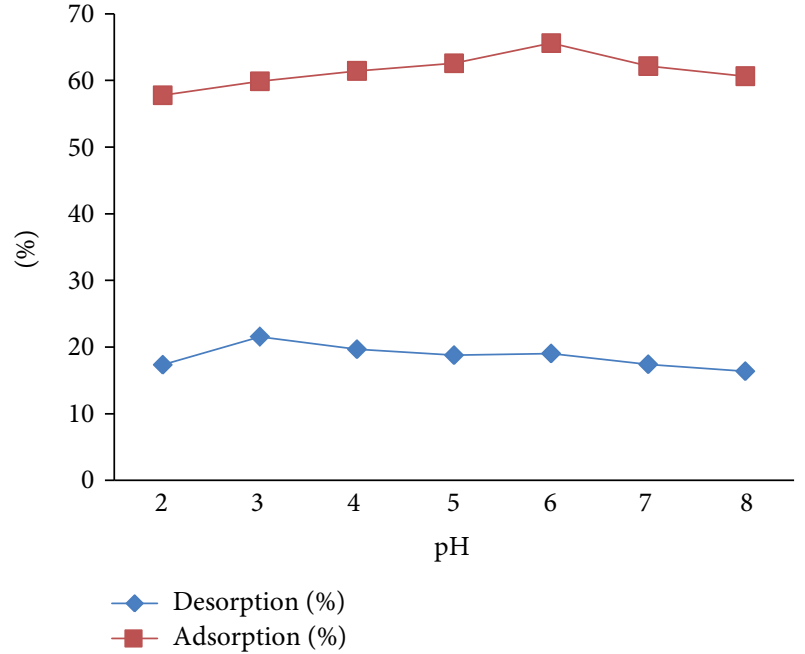

FIGURE 4: Percentage of adsorption and desorption of real industrial waste water onto MVM.

The Temkin isotherm equation (17) can be simplified to the following equation:

$$
q_{e}=\beta \ln \alpha+\beta \ln C_{e},
$$

where

$$
\beta=\frac{(R T)}{b}
$$

The constant $\beta$ is related to the heat of adsorption [20]. The adsorption data were analyzed according to the linear form of Temkin isotherm equation (18). The linear isotherm constants and coefficients of determination are presented in Table 2 . The correlation coefficients $R^{2}$ obtained from Temkin model were comparable to that obtained for Langmuir and Freundlich equations, which explains the applicability of Temkin model to the adsorption of Cr (VI) onto MVM.

It can be seen that the Langmuir isotherm fits the data better than Freundlich, D-R, and Temkin isotherms. This is also confirmed by the high value of $R^{2}$ in case of Langmuir. Moreover, among the eight errors analysis methods the Langmuir shows smaller value, which describes the better the curve fitting.
Over the past few decades, linear regression has been developed as a major option in designing the adsorption systems. However, recent investigations have indicated the growing discrepancy (between the predictions and experimental data) and disability of the model, propagating towards a different outcome. However, the expanding of the nonlinear isotherms represents a potentially viable and powerful tool, leading to the superior improvement in the area of adsorption science [21].

3.1. Desorption Studies. Regeneration of the adsorbent may make the treatment more economical and feasible. Desorption studies help to elucidate the mechanism of metal adsorption and recycling of the spent adsorbent and the metal. If the adsorbed metal can be desorbed using neutral $\mathrm{pH}$ water, then the attachment of the metal to the adsorbent is by weak bonds. The adsorption capacity and rate constant have the tendency to increase as initial $\mathrm{pH}$ of the solution increases. This is due to the $\mathrm{pH}_{\mathrm{zpc}}$ (4.4) of the adsorbents, which has an acidic value; this is favorable for cation adsorption [22]. At pH above 4.4, the carboxyl groups are deprotonated and as such are negatively charged. These negatively charged carboxylate ligands $\left(-\mathrm{COO}^{-}\right)$can attract the positively charged $\mathrm{Cr}$ (VI) molecules, and binding can occur. Thus the $\mathrm{Cr}(\mathrm{VI})^{+1}$ binding to the MVM may be ion-exchange mechanism, which may involve electrostatic interaction between the negatively charged groups in the cell walls and the metal cationic molecules. The maximum desorption of Cr (VI) onto MVM (22.34\%) is obtained at 3 pH (Figure 3).

3.2. Suitability of MVM onto Real Industrial Waste Water. The industrial waste water was collected locally from a metal finishing industry in Tirupur near to Coimbatore. The adsorption technique was carried out in the real waste water onto MVM, in order to remove the toxic metal from water. The effect of $\mathrm{pH}$, adsorption dosage, and desorption was investigated.

In this study, Initial $\mathrm{pH}$ values were adjusted in the range of 2 to 8 before addition of the adsorbent. Figure 4 show that the adsorption was highly $\mathrm{pH}$ dependent. The uptake increased with increasing $\mathrm{pH}$ up to a maximum $(0.22 \mathrm{mmol} / \mathrm{g}$ at $\mathrm{pH}$ 6) and then decreased gradually. The optimum $\mathrm{pH}$ value ( $\mathrm{pH} \mathrm{6)}$ was adjusted for further experiments. 


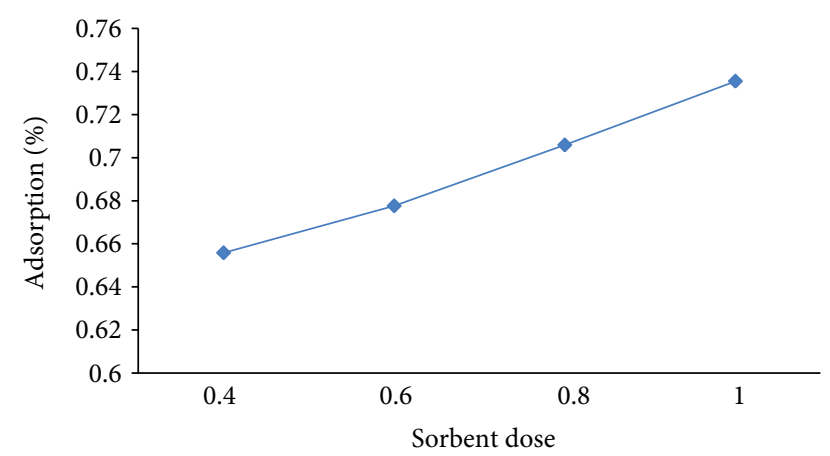

FIGURE 5: Effect of sorbent dose on the adsorption of real industrial waste water onto MVM.

The effect of changing adsorbent dosage on the adsorption rate of real industrial waste water was studied by varying the concentration of the sorbent from $0.4 \mathrm{~g}$ to $1 \mathrm{~g}$ while keeping the other experimental conditions constant. The percentage removal versus adsorbent dosage is shown in Figure 5. An increase in the percentage of adsorption with increasing adsorbent dosage was observed.

Desorption studies help to elucidate one mechanism of adsorption and recovery of the adsorbate and adsorbent. The maximum desorption of MVM from real industrial waste water is shown in Figure 4. It suggests that the recovery of metal from the adsorbent was possible and it make the process more feasible.

\section{Conclusions}

Results from this study confirmed that MVM can be used as a suitable biosorbent for $\mathrm{Cr}$ (VI) ions from aqueous solutions and in terms of real industrial waste water. The removal of $\mathrm{Cr}$ (VI) was highly dependent on solution $\mathrm{pH}$. The equilibrium data were best described by the Langmuir isotherm model, exclusively for all the error function selection methods. The recycling ability of MVM reveals that recovery of $\mathrm{Cr}$ (VI) from adsorbent was possible. The desorption experiment suggests that the $\mathrm{Cr}$ (VI) sorption is generally of an irreversible nature, owing to strong interaction between $\mathrm{Cr}_{2} \mathrm{O}_{7}{ }^{2-}$ and the surface active sites of the sorbent. Strong bonding between sorbate and sorbent does not make the regeneration of the sorbent economically viable. The Acacia nilotica leaves used in this work are freely and abundantly available. The preparation of MVM is agreeing with the principles of green chemistry, and it possesses high adsorption of $\mathrm{Cr}$ (VI) from aqueous solution and real industrial waste water.

\section{References}

[1] N. Ahalya, R. D. Kanamadi, and T. V. Ramachandra, "Cr (VI) and Fe (III) removal using Cajanus cajan husk," Journal of Environmental Biology, vol. 28, no. 4, pp. 765-769, 2007.

[2] M. Koroki, S. Saito, and H. Hashimoto, "Removal of Cr(VI) from aqueous solutions by the culm of bamboo grass treated with concentrated sulfuric acid," Environmental Chemistry Letters, vol. 8, no. 1, pp. 59-61, 2010.
[3] S. Puri, K. S. Bangarwa, and S. Singh, "Influence of multipurpose trees on agricultural crops in arid regions of Haryana, India," Journal of Arid Environments, vol. 30, no. 4, pp. 441-451, 1995.

[4] R. A. K. Rao, M. A. Khan, and B. H. Jeon, "Utilization of carbon derived from mustard oil cake (CMOC) for the removal of bivalent metal ions: effect of anionic surfactant on the removal and recovery," Journal of Hazardous Materials, vol. 173, no. 1-3, pp. 273-282, 2010.

[5] M. Hadi, M. R. Samarghandi, and G. McKay, "Equilibrium twoparameter isotherms of acid dyes sorption by activated carbons: study of residual errors," Chemical Engineering Journal, vol. 160, no. 2, pp. 408-416, 2010.

[6] S. C. Tsai and K. W. Juang, "Comparison of linear and nonlinear forms of isotherm models for strontium sorption on a sodium bentonite," Journal of Radioanalytical and Nuclear Chemistry, vol. 243, no. 3, pp. 741-746, 2000.

[7] B. H. Hameed and M. I. El-Khaiary, "Removal of basic dye from aqueous medium using a novel agricultural waste material: pumpkin seed hull," Journal of Hazardous Materials, vol. 155, no. 3, pp. 601-609, 2008.

[8] R. Ahmad and R. Kumar, "Adsorption studies of hazardous malachite green onto treated ginger waste," Journal of Environmental Management, vol. 91, no. 4, pp. 1032-1038, 2010.

[9] H. Freundlich, "Adsorption in solution," Zeitschrift für Physikalische Chemie, vol. 57, pp. 384-470, 1906.

[10] A. Altinisik, E. Gur, and Y. Seki, "A natural sorbent, Luffa cylindrica for the removal of a model basic dye," Journal of Hazardous Materials, vol. 179, no. 1-3, pp. 658-664, 2010.

[11] E. Bulut, M. Ozacar, and A. I. Sengil, "Adsorption of malachite green onto bentonite: equilibrium and kinetic studies and process design," Microporous and Mesoporous Materials, vol. 115, no. 3, pp. 234-246, 2008.

[12] I. Langmuir, "The adsorption of gases on plane surfaces of glass, mica and platinum," Journal of the American Chemical Society, vol. 40, no. 9, pp. 1361-1403, 1918.

[13] D. G. Kinniburgh, "General purpose adsorption isotherms," Environmental Science and Technology, vol. 20, no. 9, pp. 895-904, 1986.

[14] K. Fytianos, E. Voudrias, and E. Kokkalis, "Sorption-desorption behaviour of 2,4-dichlorophenol by marine sediments," Chemosphere, vol. 40, no. 1, pp. 3-6, 2000.

[15] M. M. Dubinin, "The potential theory of adsorption of gases and vapors for adsorbents with energetically nonuniform surfaces," Chemical Reviews, vol. 60, no. 2, pp. 235-266, 1960.

[16] L. V. Radushkevich, "Potential theory of sorption and structure of carbons," Zhurnal Fizicheskoi Khimii, vol. 23, pp. 1410-1420, 1949.

[17] T. Shahwan and H. N. Erten, "Temperature effects in barium sorption on natural kaolinite and chlorite-illite clays," Journal of Radioanalytical and Nuclear Chemistry, vol. 260, no. 1, pp. 43-48, 2004.

[18] J. P. Hobson, "Physical adsorption isotherms extending from ultrahigh vacuum to vapor pressure," Journal of Physical Chemistry, vol. 73, no. 8, pp. 2720-2727, 1969.

[19] M. J. Temkin and V. Pyzhey, "Recent modifications to Langmuir isotherms," Acta Physiochimica U.S.S.R., vol. 12, pp. 217-222, 1940.

[20] C. I. Pearce, J. R. Lioyd, and J. T. Guthrie, “The removal of colour from textile wastewater using whole bacterial cells: a review," Dyes and Pigments, vol. 58, no. 3, pp. 179-196, 2003. 
[21] K. Y. Foo and B. H. Hameed, "Insights into the modeling of adsorption isotherm systems," Chemical Engineering Journal, vol. 156, no. 1, pp. 2-10, 2010.

[22] D. Prahas, Y. Kartika, N. Indraswati, and S. Ismadji, "The use of activated carbon prepared from Jackfruit (Artocarpus heterophyllus) peel waste for methylene blue removal," Journal of Environmental and Protection Science, vol. 2, pp. 1-10, 2008. 

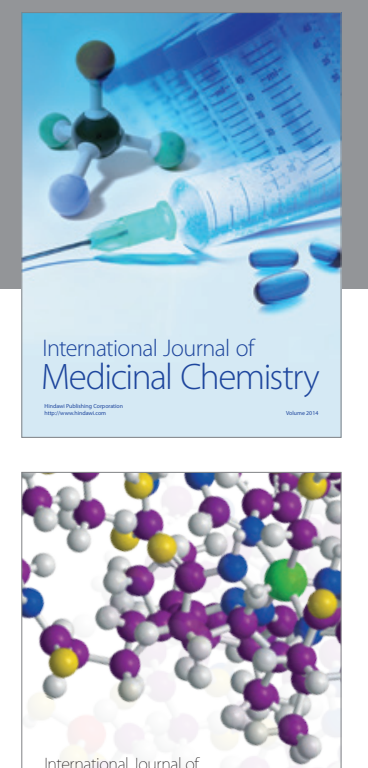

\section{Carbohydrate} Chemistry

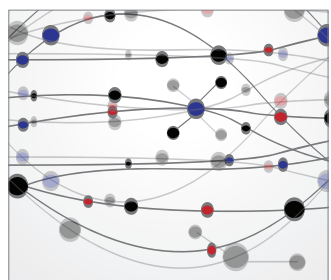

The Scientific World Journal
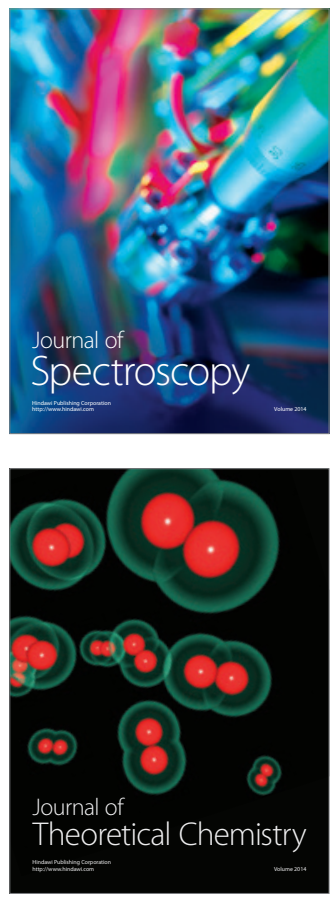
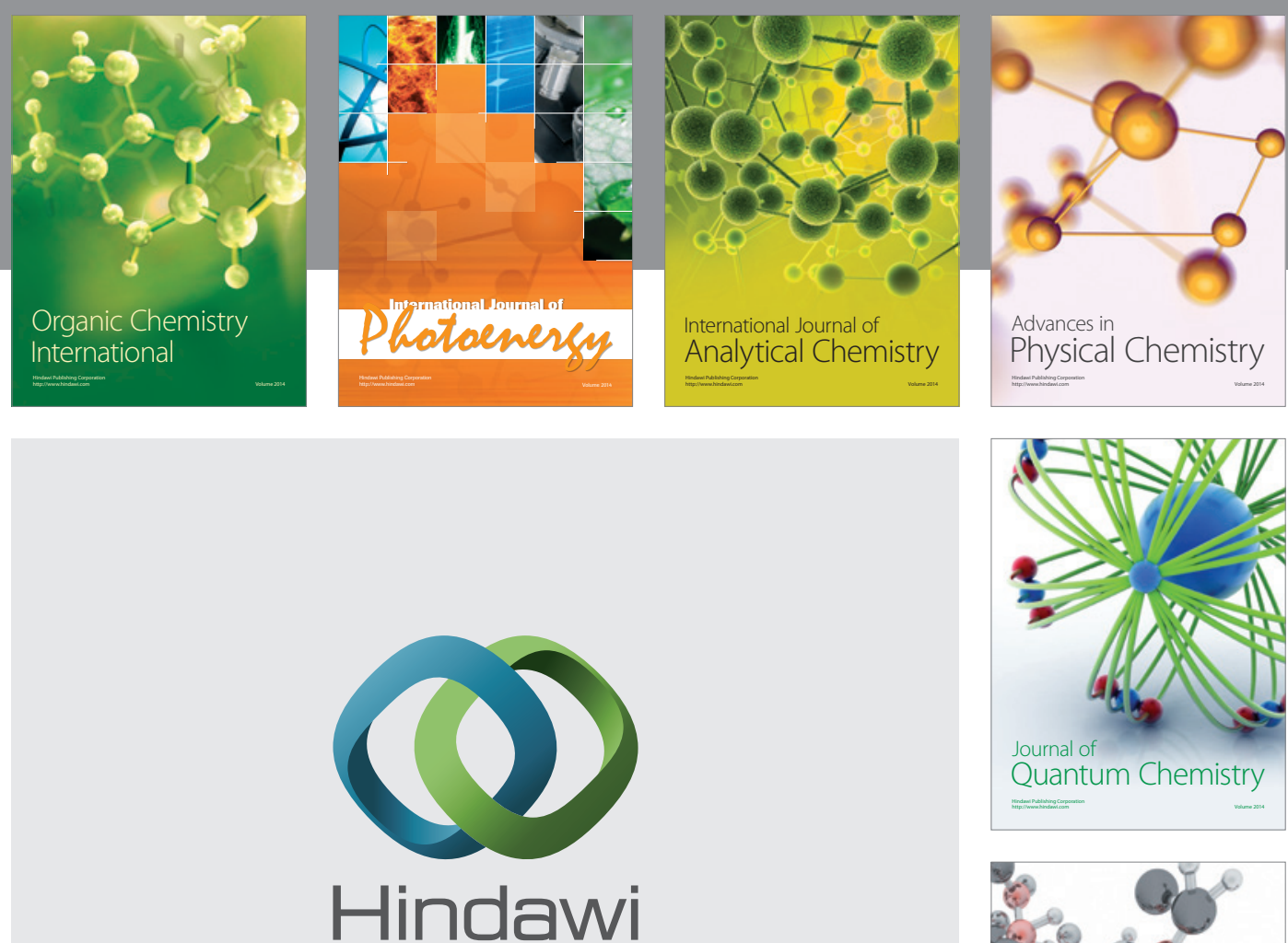

Submit your manuscripts at

http://www.hindawi.com

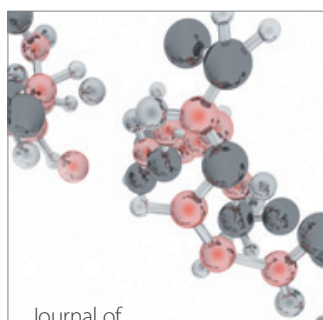

Analytical Methods

in Chemistry

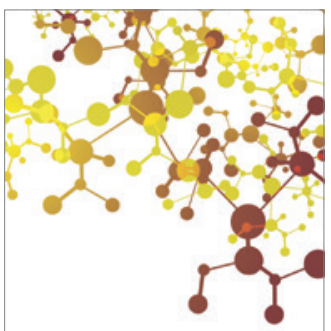

Journal of

Applied Chemistry

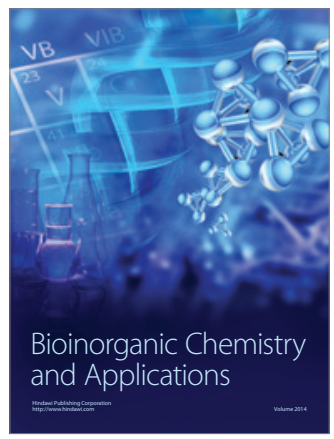

Inorganic Chemistry
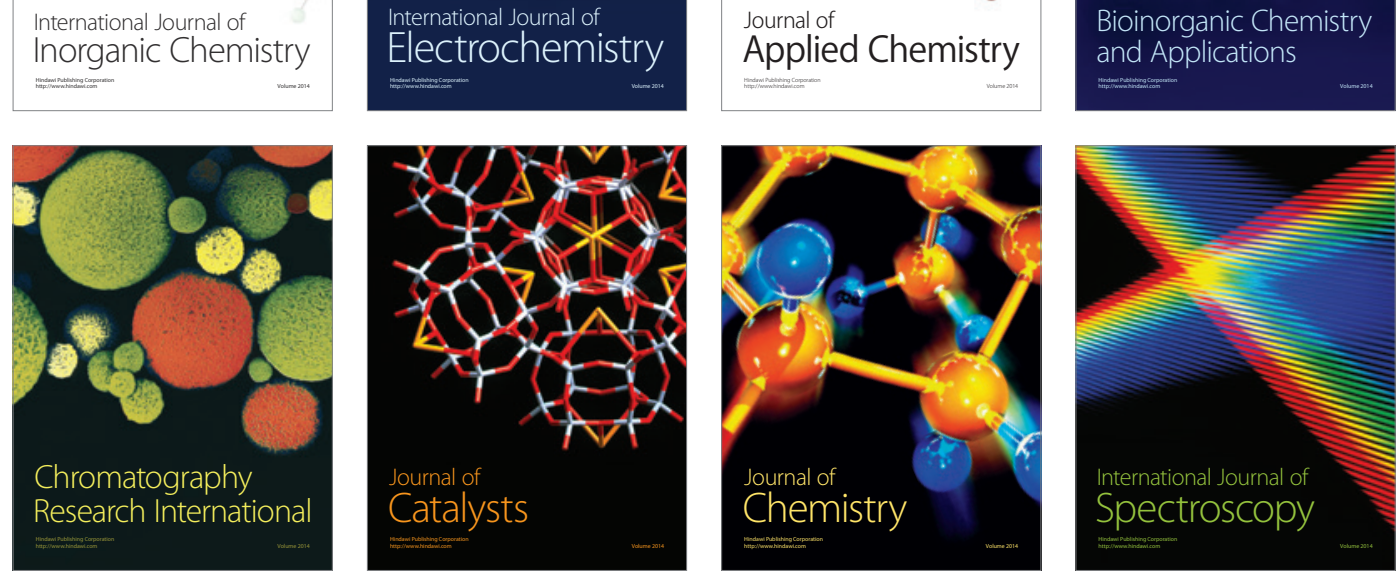